Does Asthma Impair Wealth Accumulation or Does Wealth Protect Against Asthma?

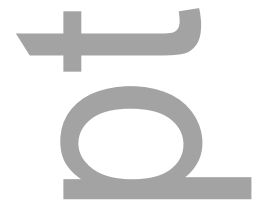

$\square$

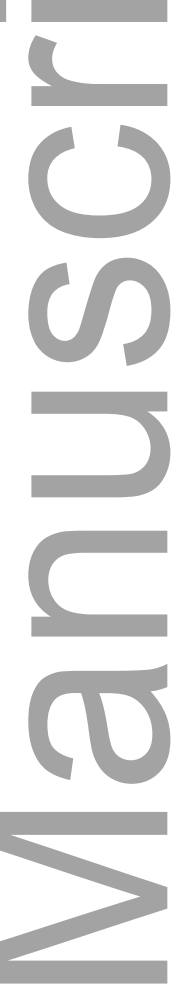

Jay L. Zagorsky

Center for Human Resource Research

Ohio State University

921 Chatham Lane, Suite 100

Columbus OH 43221 USA

zagorsky.1@osu.edu

$+1-614-442-7300$ (office)

$+1-614-442-7329$ (fax)

Jay L. Zagorsky shall share all data and coding for replication purposes.

Direct all other correspondence to Patricia K. Smith

$$
\begin{gathered}
\text { Patricia K. Smith * } \\
\text { Department of Social Sciences } \\
\text { University of Michigan-Dearborn } \\
4901 \text { Evergreen Road } \\
\text { Dearborn MI 48128 USA } \\
\text { pksmith@umich.edu } \\
+1-313-593-5205 \text { (office) } \\
+1-313-593-5645 \text { (fax) }
\end{gathered}
$$

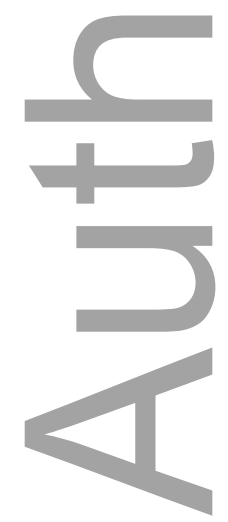

This is the author manuscript accepted for publication and has undergone full peer review but has not been through the copyediting, typesetting, pagination and proofreading process, which may lead to differences between this version and the Version of Record. Please cite this article as doi: $\underline{10.1111 / \text { ssqu. } 12293 .}$.

This article is protected by copyright. All rights reserved. 
Abstract

Objective: We investigate the association between adult asthma and wealth, testing whether the disease impairs wealth accumulation (social selection model) or if wealth protects against asthma (social causation model).

Methods: We use the National Longitudinal Survey of Youth $(n=7,644)$ and linear and logistic regressions to estimate the association between wealth and asthma. Changes in relative wealth following an asthma diagnosis and asthma status by increases in wealth through inheritance provide evidence on the causal direction.

Results: Asthma, particularly severe asthma, is associated with lower wealth. Wealth ranking does not change after a diagnosis of asthma, but inheriting a substantial sum is associated with a lower risk of severe asthma.

Conclusion: Wealth appears to protect against severe asthma, supporting the social causation model of disease.

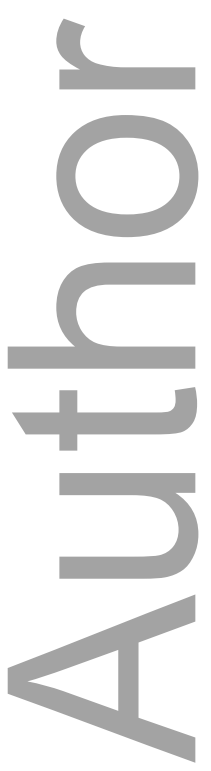

This article is protected by copyright. All rights reserved. 


\section{Does Asthma Impair Wealth Accumulation or Does Wealth Protect Against Asthma?}

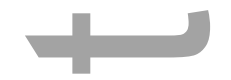

Understanding the causes and consequences of asthma is increasingly important because its prevalence has been steadily rising in the U.S. The National Health Interview Survey (NHIS) shows that between 2001 and 2013 adult asthma prevalence rose by 8.3\% (CDC 2013). In 2013 ten percent of men and 13 percent of women reported ever receiving a diagnosis of asthma (CDC 2013). The American Lung Association (2012) estimates that asthma costs society roughly $\$ 50.1$ billion in direct medical expenditures and $\$ 5.9$ billion in indirect costs (reduced labor productivity), for a total of $\$ 56$ billion annually. Corso and Fertig (2009) estimate that children born in 2000 who develop asthma will generate $\$ 3.2$ billion in medical costs and $\$ 4$ billion in lost labor productivity over the course of their lives. Lower productivity can lead to lower earnings and wealth among asthmatics. These substantial costs prompt policymakers' interest in asthma's prevention and treatment.

This paper is the first to use nationally representative U.S. longitudinal data to investigate the association between adult asthma and wealth. We test three hypotheses: (1) asthma and wealth are inversely related; (2) asthma reduces wealth (social selection model); and (3) wealth reduces asthma (social causation model). Regressions show that asthma and wealth are indeed inversely related. Additional tests find no evidence that the onset of asthma is associated with a change in relative wealth, but an increase in wealth through inheritance is associated with a lower risk of severe asthma. These results offer qualified support for the social causation hypothesis -socioeconomic status (SES), measured as wealth, protects against severe asthma.

\section{Background}

Two strands of literature lay the groundwork for this study: the health-SES relationship in general and the asthma-SES relationship in particular. While the evidence is clear that health and SES are related, how they are related remains murky (Adler and Stewart 2010; Duncan et al. 2002; Goldman 2006; Mulatu and Schooler 2002; Pollack et al. 2007). The social causation model theorizes This article is protected by copyright. All rights reserved. 
that SES causes health, predicting that income and wealth enable individuals to acquire the resources needed to produce and maintain health (Link and Phelan 1995; Wheaton 1978). The social selection model posits the reverse causal pattern; health causes SES (Eaton 1980; West 1991), and implies poor health impairs the ability to earn income and accumulate wealth. Both models predict an SES gradient in disease prevalence.

Because SES is related to health in general, it is reasonable to suspect it is related to asthma in particular. Indeed, descriptive analyses of adult asthma prevalence in the U.S. confirm an income gradient; lower income individuals exhibit the highest asthma prevalence and the rate drops as income rises (Akinbami et al. 2011; Zhang et al. 2013). Which model, social causation or social selection best explains this pattern?

First, we consider the evidence supporting the social selection model. Like any chronic illness in adulthood, asthma can reduce the ability to earn income and requires out-of-pocket medical expenditures, which may divert money from savings and investment. Unlike other chronic diseases, however, asthma is common among working-age adults and thus may have a larger impact on labor market participation than illnesses that tend to strike later in life (Blanc 2000).

The evidence that asthma adversely affects labor market participation is compelling. While asthma ranks relatively low as a source of Years of Life Lost (YLL) and number of deaths, it ranks $24^{\text {th }}$ among causes of Disability-Adjusted Life-Years (DALYs) and tenth among causes of Years Lived with Disability (YLD) (U.S. Burden of Disease Collaborators 2013). Not surprisingly, severe asthma is associated with a greater risk of work disability (Balder et al. 1998). Druss et al. (2002) report that asthma ranks seventh among top causes of work-loss days. Estimates of work days lost due to asthma range from 2.1 million (Smith et al. 1997) to 3 million (Weiss et al. 1992).

Asthma may reduce productivity not only by reducing work days, but also by raising the risk of unemployment. Studies of asthma's association with unemployment find effects that range from small (Sibbald et al. 1992; Wilson 2001) to moderate (Ameille et al. 1997; Blanc et al. 2001). Given the negative impact of asthma on labor, it's not surprising that the disease is associated with lower This article is protected by copyright. All rights reserved. 
earnings. Two studies report that the onset of occupational asthma is associated with income declines of 35\% to 50\% (Ameille et al. 1997; Gannon et al. 1993). These adverse labor market outcomes among asthmatics support the social selection model.

Asthma may reduce lifetime earnings by hastening retirement. In a sample of respondents aged 55 to 75, asthma was associated with an increased risk of early retirement (Yelin et al. 2006). However, Miah and Wilcox-Gök (2007) report that among workers ages 51 to 61, chronic illnesses, such as asthma, are associated with delayed retirement because they reduce wealth - workers can't afford to retire. Absenteeism, disability, unemployment and possibly early retirement all reduce lifetime earnings and thus the ability to accumulate wealth, consistent with the social selection model.

While the literature suggests asthma's adverse impact on earnings is substantial, the available evidence suggests that treatment costs to individuals are modest. The 1996 Medical Expenditure Panel Survey (MEPS) shows that among individuals who received asthma treatment, the per capita cost averaged $\$ 663$, of which about $\$ 252$ was paid out-of-pocket (Druss et al. 2001). Barnett and Nurmagambetov (2011) use MEPS data from 2002 to 2007 and estimate treatment costs at $\$ 3,259$, but do not disaggregate costs paid out-of-pocket versus those paid by insurance. The available evidence suggests asthma treatment does not divert large amounts of money away from savings and investment. If asthma causes SES, causality likely flows through reduced labor productivity rather than through lower savings and investment.

In contrast to the social selection model, the social causation model posits that SES causes asthma (Chen and Schreier 2009). However, less is known about asthma's causes than about factors that increase its morbidity (Gold and Wright 2005). Notably, environmental factors worsen asthma symptoms (Global Initiative for Asthma 2011; Institute of Medicine 2000). Wealthier people can use their financial resources to live in areas with fewer environmental risk factors, stressors, and can more frequently clean/replace household items that aggravate asthma symptoms. Moreover, 
wealthier individuals can buy better quality medical care, enabling them to dampen the impact of asthma.

The social causation model also garners some empirical support, although no studies examine asthma specifically. Jackson et al. (2004) find a gradient in children's respiratory health, measured as forced expiratory volume in one second (FEV1) and forced vital capacity (FVC), using parental educational to measure SES. Two studies produce evidence that adult pulmonary disease is associated with childhood SES, measured by parental income, education, or occupation (Prescott and Vestbo 1999; Ramsay et al. 2011). Three studies present evidence that characteristics of the physical environment in which the poor can afford to live trigger asthma symptoms (Katz et al. 2001; Neidell 2004; Rosenbaum 2008). Overall, the literature on the social causation model offers some support for the hypothesis that SES causes asthma, with greater SES protecting against asthma.

Studies of both models of disease frequently use income to measure SES, a flow measure of a person's available resources. None use wealth, which measures the stock of resources available. Wealth can provide a better measure of a person's ability to purchase goods and services, as Bernard et al. (2009) demonstrate in the case of health insurance.

\section{Data and Methods}

This analysis uses the National Longitudinal Survey of Youth (NLSY79) to track asthma prevalence and wealth among adult Americans born between 1957 and 1964 (baby boomers). The NLSY79 is a stratified, multistage area sample covering the entire U.S (Zagorsky 1997). It has tracked the lives of 12,686 individuals since 1979; however because of attrition and funding cutbacks this study examines only 7,644 . We use survey weights to correct for the over-sampling of poor individuals, Blacks, and Hispanics and for the complex sample design.

This article is protected by copyright. All rights reserved. 


\section{Asthma Status}

In 2004 the NLSY79 included a one-time asthma module. Asthma information was gathered for 852 respondents (out of 7,650) who affirmatively answered the question: "Has a doctor, nurse or other health professional ever told you that you have asthma?" Six respondents reported they did not know whether they had asthma and were dropped from the analysis. Six asthma indicators were created. First, "Ever Had Asthma" indicates whether a respondent reported they had ever been diagnosed with asthma. Second, "Currently Has Asthma" identifies respondents reporting they had the condition at the time of the survey. Third, "Previously Had Asthma" accounts for respondents who had been diagnosed with asthma, but did not report suffering from it at the time of the interview. The fourth indicator, "Current Severe Asthma," is defined as individuals with current asthma who reported at least one of the following: During the past 12 months they made an unscheduled trip to an emergency room, doctor, or urgent care center because of asthma; during the past 12 months asthma limited their usual activities a fair amount to a lot; asthma made it difficult to stay asleep at night at least once a week over the past 30 days. Respondents were also categorized as having severe asthma if they reported experiencing symptoms multiple times weekly. Variations in the definition of severe asthma were explored, but they did not impact the results because most people with severe asthma reported multiple events. Fifth, "No Asthma" means the respondent reported they had never been diagnosed with the disease.

The final disease indicator variable is "Years of Asthma." Respondents were asked their age when asthma was first diagnosed. For those respondents who stated they no longer suffered from asthma, the age or date when the condition stopped was recorded. For respondents who reported current asthma, age on the survey date was recorded. Subtracting these time values provides the number of years a respondent has had asthma. Unfortunately, the NLSY79 does not contain any information on whether respondents have a family of history of asthma, which can affect asthma risk (Gorman and Asaithambi 2008).

This article is protected by copyright. All rights reserved. 
About eleven percent of sample reported having been diagnosed with asthma at some point in their lives, with males reporting lower rates than females, $8 \%$ vs. $12.8 \%$ (Table 1 ). This gender difference is consistent with asthma prevalence patterns reported in the National Health Interview Survey (CDC 2013) and the Behavioral Risk Factor Surveillance Survey (CDC 2012). About half of those who currently have asthma have a severe case, with men reporting lower rates of severe asthma than women.

(Table 1 about here)

\section{Wealth}
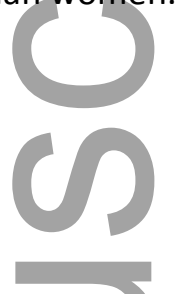

One strength of the NLSY79 is that respondents regularly report each of their debts and assets. Summing the current market values of the assets and subtracting the total debts creates the wealth measure for each survey wave (Zagorsky 1999). This analysis uses wealth in 2004, the year of the asthma module. Because the top $1 \%$ of wealth values is top-coded to ensure privacy we exclude those 150 cases to prevent any distortions.

Table 2 reports the sample's demographic characteristics by asthma status. Whites are somewhat under-represented among asthmatics, while Blacks, Hispanics, and women are overrepresented. Income is negatively associated with asthma and the more severe or current the condition, the lower is income. For example, the average income of those who have never had asthma was $\$ 77,937$ compared to $\$ 52,371$ for those with severe asthma. Furthermore, asthmatics work nearly two years less than people who have never had the disease (18 vs. 19.9). In addition to race, gender, income and employment, the analyses include control for age, education, number of siblings, marital status, geographic location, and smoking.

(Table 2 about here)

\section{Results}

This article is protected by copyright. All rights reserved. 
We begin by testing hypothesis (1): asthma and wealth are inversely related. Table 3

presents the wealth distribution by asthma status. Adults who have never had asthma reported a median net worth of $\$ 102,854$, which is roughly double that of respondents who currently have asthma $(\$ 52,384)$ and triple that of those with severe asthma $(\$ 30,506)$. Across gender, race, and ethnicity, those who have never had asthma are wealthier than those who currently have asthma, who in turn are wealthier than those with severe asthma. These descriptive results support the hypothesis that asthma and wealth are inversely related.

(Table 3 about here)

Table 4 presents regression estimates of wealth as a function of asthma status ("no asthma" is the omitted category) controlling for an array of demographic variables. Only severe asthma is statistically significantly related to wealth and is associated with a drop in wealth of over $\$ 24,000$. Thus, hypothesis 1 receives qualified support; asthma and wealth are inversely related when the disease is severe. We also ran regressions using the natural log of wealth to adjust for skewness in the distribution (not shown for space reasons). The natural log regressions produced evidence of an inverse association between wealth and ever having asthma as well as severe asthma.

(Table 4 about here)

Adding "years of asthma" to the reported regression as well as to the log wealth regressions (not shown) results in statistically insignificant coefficients. This suggests either the length of time a person has had asthma is not associated with wealth or respondents do not accurately recall when their asthma was diagnosed.

These regressions presume wealth depends on asthma. Reversing these roles shows the association between wealth and the risk of asthma. We estimate logistic regressions for each of the four asthma statuses relative to "no asthma," controlling for the demographic variables included in the previous regressions (results available upon request). Wealth is inversely related to the risk of asthma in all these regressions, but is statistically significant at the $5 \%$ level only for severe asthma 
(coefficient of -0.008). This result also offers qualified support for hypothesis 1 : asthma and wealth are inversely related when the disease is severe.

In order to better understand what the estimated logistic coefficient for wealth means for the risk of severe asthma, we follow the three step process outlined by Pindyck and Rubinfeld (1998) to present an example for a typical respondent. A 45-year-old white, divorced woman with $\$ 40,000$ income, no net worth, who graduated high school, has three siblings, worked for 15 years and lives in an urban area, has a $7.5 \%$ chance of having severe asthma based on the coefficients in the logistic regression. However, increasing her wealth from zero to $\$ 50,000$, holding the other regressors constant, lowers her chance of severe asthma to $5.2 \%$, almost a one-third reduction in risk. Raising her wealth to the median drops her probability of having severe asthma to $3.5 \%$, a risk reduction of over one-half. Unfortunately, previous studies use measures other than asthma prevalence in assessing asthma risk reduction, rendering comparison of our results to prior findings invalid. However, a physician specializing in asthma judged the risk reductions of one-third to one-half simulated here to be clinically significant (Baptist 2015).

The results thus far indicate that asthma and wealth are inversely related, but shed no light on the direction of causality. While respondents cannot be randomly assigned to treatment and control groups, the longitudinal nature of the NSLY79 provides some evidence on the likely direction of causality. Respondents have provided wealth information at numerous points in their lives, so individuals who reported first having asthma when they were in their twenties or older have wealth information before and after they became asthmatic. These data can be used to test hypothesis (2): asthma causes wealth. If becoming asthmatic adversely impacts wealth per the social selection model, respondents would experience wealth declines after the onset of asthma.

Figure 1 shows the average change in a respondent's ranking in the wealth distribution (relative wealth) following asthma diagnosis. Using relative rather than absolute wealth controls for fluctuations in the U.S. economy over the observation period. Wealth ranking ranges from zero to 100 percent and represents the fraction of people lower in the wealth distribution than the 
respondent. For example, a value of 33\% in 1988 and 25\% in 1990 means the respondent was wealthier than one-third of the cohort in 1988, but by 1990 was wealthier than just one-quarter, i.e. the respondent's relative wealth dropped. Because respondents received their asthma diagnosis in different years, we center this analysis on the year of diagnosis and compare wealth ranking one year before asthma diagnosis to wealth rankings one to five years afterwards.

(Figure 1 about here)

One year prior to diagnosis the typical asthmatic was wealthier than $43 \%$ of the cohort. After receiving the diagnosis, the median asthmatic's wealth ranking fell only slightly, to about $41 \%$ on average across the five years examined. This suggests relative wealth does not decline much after an asthma diagnosis, failing to support hypothesis 2 (social selection).

Finally, we test hypothesis 3: wealth protects against asthma (social causation). We searched the NLSY79 for situations where individual wealth changes exogenously. If wealth protects against asthma, then respondents who received increases in wealth would exhibit lower asthma prevalence or severity. The NLSY79 includes information on the receipt of inheritances and large monetary gifts, which constitute an increase in wealth; however inheritances may not be entirely exogenous.

Table 5 compares severe asthma prevalence between respondents who received substantial inheritances/gifts to those who did not. Columns (1) and (2) show that among those getting little or no inheritance/gift, roughly half had severe asthma (49.8\% to $50.7 \%)$. In contrast, columns (3) an (4) show that among those who inherited a substantial amount of money, only about one-third had severe asthma (33.8\% to $38 \%$ ). Moreover, the percentage with severe asthma drops as the size of the inheritance increases. Logistic regressions estimating the association between inheritance and the risk of severe asthma adjusting for demographic and other factors (not shown for space reasons) corroborate the findings of table 4 and indicate the more money a person inherits the lower the risk (1)

of severe asthma. These results suggest increases in wealth reduce the prevalence of severe asthma, consistent with hypothesis (3), social causation model.

(Table 5 about here)

This article is protected by copyright. All rights reserved. 


\title{
Conclusion
}

\begin{abstract}
This research investigated the relationship between adult asthma and wealth using the National Longitudinal Survey of Youth 1979 (NLSY79), a nationally representative sample of U.S. baby boomers. Linear and logistic regressions controlling for an array of socioeconomic and demographic factors show that wealth and severe asthma are inversely related. Respondents who have severe asthma report a net worth approximately $\$ 24,500$ lower than those who have never
\end{abstract} had the disease. According to the logistic regression coefficients, substantial increases in wealth are associated with a decrease in the risk of severe asthma of between one-third and one-half.

Additional tests suggest that wealth protects against severe asthma (social causation), but do not support the hypothesis that asthma impairs wealth accumulation (social selection). Overall, this research suggests wealth is more a cause than a consequence of asthma. This finding strengthens the accumulating evidence that SES influences health and that socioeconomic inequality contributes to inequalities in the burden of disease.

With respect to policy, the results do not indicate that improving asthma prevention and treatment programs will improve individual wealth, although they would improve asthmatics' quality of life and productivity. Instead, our findings suggest that policies that increase the ability to save and invest could reduce asthma severity and its associated costs. In addition, policies that weaken the link between wealth and asthma could reduce the burden of this disease among those in the lower tail of the wealth distribution. For example, policies that improve the environmental quality of locations where low-SES individuals live (e.g., changes in traffic management that reduce air pollution) and increase their access to health care (e.g., the Affordable Care Act) could improve their respiratory health.

Finally, some caveats must be noted. First, these findings apply to a specific cohort of U.S. adults, individuals in other countries and in other age ranges may have a different asthma-wealth relationship. Second, while the results suggest a causal relationship running from wealth to severe 
asthma, causality cannot be proven because it is impossible to run a controlled experiment that randomly assigns individuals to particular asthma and wealth categories. Finally, while the analyses control for many important factors, it remains possible that wealth and asthma are both related to a missing factor, or common set of factors, that actually drive the relationship.

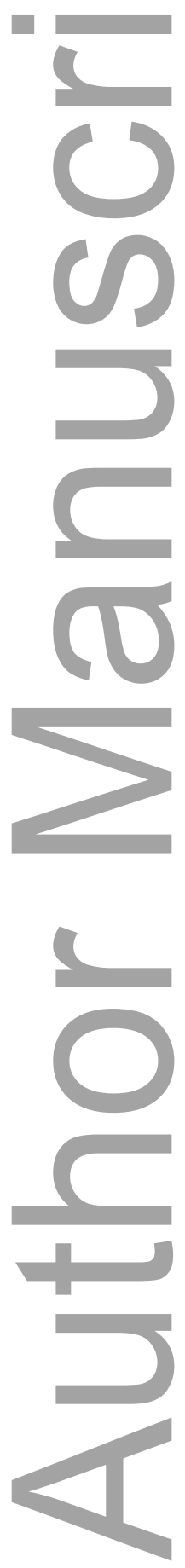

This article is protected by copyright. All rights reserved. 


\section{REFERENCES}

Adler, N. and J. Stewart. 2010. “Health Disparities across the Lifespan: Meaning, Methods, and Mechanisms," Annals of the New York Academy of Sciences 1186:5-23.

Akinbami, L., Moorman, J. and X. Liu. 2001. “Asthma Prevalence, Health Care Use, and Mortality United States, 2005-2009," National Health Statistics Reports 32 (January 12, 2011).

Ameille, J., Pairon, J., Bayeux, M. Choudat, D., Conso, F., Devienne, A., Garnier, R. and Y. Iwatsubo. 1997. "Consequences of Occupational Asthma on Employment and Financial Status: A Follow-up Study," European Respiratory Journal 10: 55-58.

American Lung Association. 2012. Trends in Asthma Morbidity and Mortality. Epidemiology and Statistics Unit, Research and Program Services Division, September 2012.

Balder, B., Lindholm, N., Löwhagen, O., Palmqvist, M., Plaschke, P., Tunsäter, A., and K. Torén. 1998. "Predictors of Self-Assessed Work Ability among Subjects with Recent- onset Asthma," Respiratory Medicine 92: 729-34.

Baptist, A. 2015. Personal communication from Associate Chief of Research at the University of Michigan Hospital - Allergy/Immunology, April 24, 2015.

Barnett, S. and T. Nurmagambetov. 2011. “Costs of Asthma in the United States: 2002-2007," Journal of Allergy and Clinical Immunology 127(1): 145-52.

Bernard, D., Banthin, J., and W. Encinosa. 2009. "Wealth, Income, and the Affordability of Health Insurance," Health Affairs 28(3): 887-96.

Blanc, P. 2000. "Characterizing the Occupational Impact of Asthma." Pp. 55 - 76 in Asthma's Impact on Society: The Social and Economic Burden, edited by K. Weiss, A. Buist, and S. Sullivan. New York: Marcel Dekker.

Blanc, P., Trupin, L., Eisner, M., Earnest, G., Katz, P., Israel, L. and E. Yelin, E. 2001. “The Work Impact of Asthma and Rhinitis: Findings from a Population-based Survey," Journal of Clinical Epidemiology 54: 610-18.

This article is protected by copyright. All rights reserved. 
CDC 2013. Centers for Disease Control and Prevention 2013 National Health Interview Survey Data, tables 2-1 and 4-1, www.cdc.gov/asthma/nhis/2013/data.htm.

CDC 2012. Centers for Disease Control and Prevention 2010 Behavioral Risk Factor Surveillance Survey, tables L2.1 and C2.1, www.cdc.gov/asthma/brfss/2010/brfssdata.htm

Chen, E. and H. Schreier. 2009. "Socioeconomic Status and Asthma in Children." Pp. $427-440$ in Allergy Frontiers: Epigenetics, Allergens, and Risk Factors, edited by R. Pawankar, S. Holgate, and L. Rosenwasser: Tokyo: Springer Japan.

Corso, P. and A. Fertig. 2009. "The Long-term Economic Costs of Asthma," Issue Paper n. 3, Partnership for America's Economic Success, Washington D.C.

Druss, B., Marcus, S., Olfson, M., and H. Pincus. 2002. "The Most Expensive Medical Conditions in America," Health Affairs 21(4): 105-11.

Druss, B., Marcus, S., Olfson, M., Tanielian, T., Elinson, L., and H. Pincus. 2001. “Comparing the National Burden of Five Chronic Conditions," Health Affairs 20(6): 233-41.

Duncan, G., Daly, M., McDonough, P., and D. Williams. 2002. “Optimal Indicators of Socioeconomic Status for Health Research," American Journal of Public Health 92(7): 1151-57.

Eaton, W. 1980. "A Formal Theory of Selection for Schizophrenia," American Journal of Sociology 86(1): 149-58.

Gannon, P., Weir, D., Robertson, A. and P. Burge. 1993. "Health, Employment, and Financial Outcomes in Workers with Occupational Asthma," British Journal of Industrial Medicine 50: 491-96.

Global Initiative for Asthma. 2011. GINA Report, Global Strategy for Asthma Management and Prevention 2011 (Update). www.ginasthma.org/documents/4

Gold, D. and R. Wright. 2005. "Population Disparities in Asthma," Annual Review of Public Health 26: 89113.

Goldman, N. 2006. "Social Inequalities in Health: Disentangling the Underlying Mechanisms," Annals of the New York Academy of Sciences 954(1):118-39. 
Gorman, B. and R. Asaithambi. 2008. "Biology, Social Environment, and Health: How Family History and Social Conditions Affect Adult Asthma," Social Science Quarterly 89(3):728-50.

Institute of Medicine. 2000. Clearing the Air: Asthma and Indoor Air Exposures. Washington D.C: National Academy Press.

Jackson, B., Kubzansky, L., Cohen, S., Weiss, S. and R. Wright. 2004. “A Matter of Life and Breath:

Childhood Socioeconomic Status is related to Young Adult Pulmonary Function in the CARDIA Study," International Journal of Epidemiology 33(2):271-278.

Katz, L., J. Kling, and J. Liebman. 2001. “Moving to Opportunity in Boston: Early Results of a Randomized Mobility Experiment," Quarterly Journal of Economics 116(2): 607-54.

Link, B. and J. Phelan. 1995. "Social Conditions as Fundamental Causes of Disease," Journal of Health and Social Behavior 35(Extra Issue): 80-94.

Miah, M. and V. Wilcox-Gök. 2007. "Do the Sick Retire Early? Chronic Illness, Asset Accumulation and Early Retirement," Applied Economics 39: 1921-36.

Mulatu, M. and C. Schooler. 2002. "Causal Connections between Socio-economic Status and Health: Reciprocal Effects and Mediating Mechanisms," Journal of Health and Social Behavior 43(1): 22-41.

Neidell. M. 2004. “Air Pollution, Health, and Socio-economic Status: The Effect of Outdoor Air Quality on Childhood Asthma," Journal of Health Economics 23: 1209-1236.

Pindyck, R. and D. Rubinfeld. 1998. Econometric Models and Economic Forecasts. 4th ed. Boston, MA: Irwin/McGraw-Hill, pp.307-317.

Pollack, C., Chideya, S., Cubbin, C., Williams, B., Dekker, M. and P. Braveman. 2007. "Should Health Studies Measure Wealth? A Systematic Review," American Journal of Preventive Medicine 33(3): 250-264.

Prescott, E. and J.Vestbo. 1999. "Socioeconomic Status and Chronic Obstructive Pulmonary Disease," Thorax 54:737-741.

This article is protected by copyright. All rights reserved. 
Ramsay, S., Whincup, P., Lenno, L., Morris, R., and S. Wannamethee. 2011. "Longitudinal Associations of Socioeconomic Position in Childhood and Adulthood with Decline in Lung Function over 20 Years: Results from a Population-based Cohort of British Men," Thorax 66: 1058-64.

Rosenbaum, E. 2008. "Racial/Ethnic Differences in Asthma Prevalence: The Role of Housing and Neighborhood Environments," Journal of Health and Social Behavior 49(2): 131-145.

Sibbald, B., Anderson, H. and S. McGuigan. 1992. "Asthma and Employment in Young Adults," Thorax 47: 19-24.

Smith, D., Malone, D., Lawson, K., Okamoto, L., Battista, C. and W. Saunders. 1997. “A National Estimate of the Economic Costs of Asthma," American Journal of Respiratory Critical Care Medicine 156: 78793.

U.S. Burden of Disease Collaborators. 2013. "The State of U.S. Health, 1990-2010: Burden of Diseases, Injuries, and Risk Factors," JAMA 310(6): 591-606.

Weiss, K., Gergen, P. and T. Hodgson. 1992. "An Economic Evaluation of Asthma in the United States," New England Journal of Medicine 326(13): 862-66.

West, P. 1991. "Rethinking the Health Selection Explanation for Health Inequalities," Social Science \& Medicine 32(4):373-84.

Wheaton, B. 1978. "The Sociogenesis of Psychological Disorder: Reexamining the Causal Issues with Longitudinal Data," American Sociological Review 43(3): 383-403.

Wilson, S. 2001. "Work and the Accommodation of Chronic Illness: A Re-examination of the Health-Labor Supply Relationship," Applied Economics 33(9): 1139, Bus. Coll.: 13371436

Yelin, E., Katz, P., Balmes, J., Trupin, L., Earnest, G., Eisner, M. and P. Blanc. 2006. “Work Life of Persons with Asthma, Rhinitis, and COPD: A Study using a National, Population-based Sample," Journal of Occupational Medicine and Toxicology 1:2 doi:10.1186/1745- 6673-1-2.

Zagorsky J. 1997. NLSY79 Users' Guide. Columbus, Ohio: The Ohio State University.

Zagorsky J. 1999. "Young Baby Boomers' Wealth," Review of Income and Wealth 45:135-56.

This article is protected by copyright. All rights reserved. 
Zhang, X., Morrison-Carpenter, T., Holt, J., and D. Callahan. 2013. "Trends in Adult Current Asthma Prevalence and Contributing Risk Factors in the United States by State: 2000-2009," BMC Public Health 13:1156.

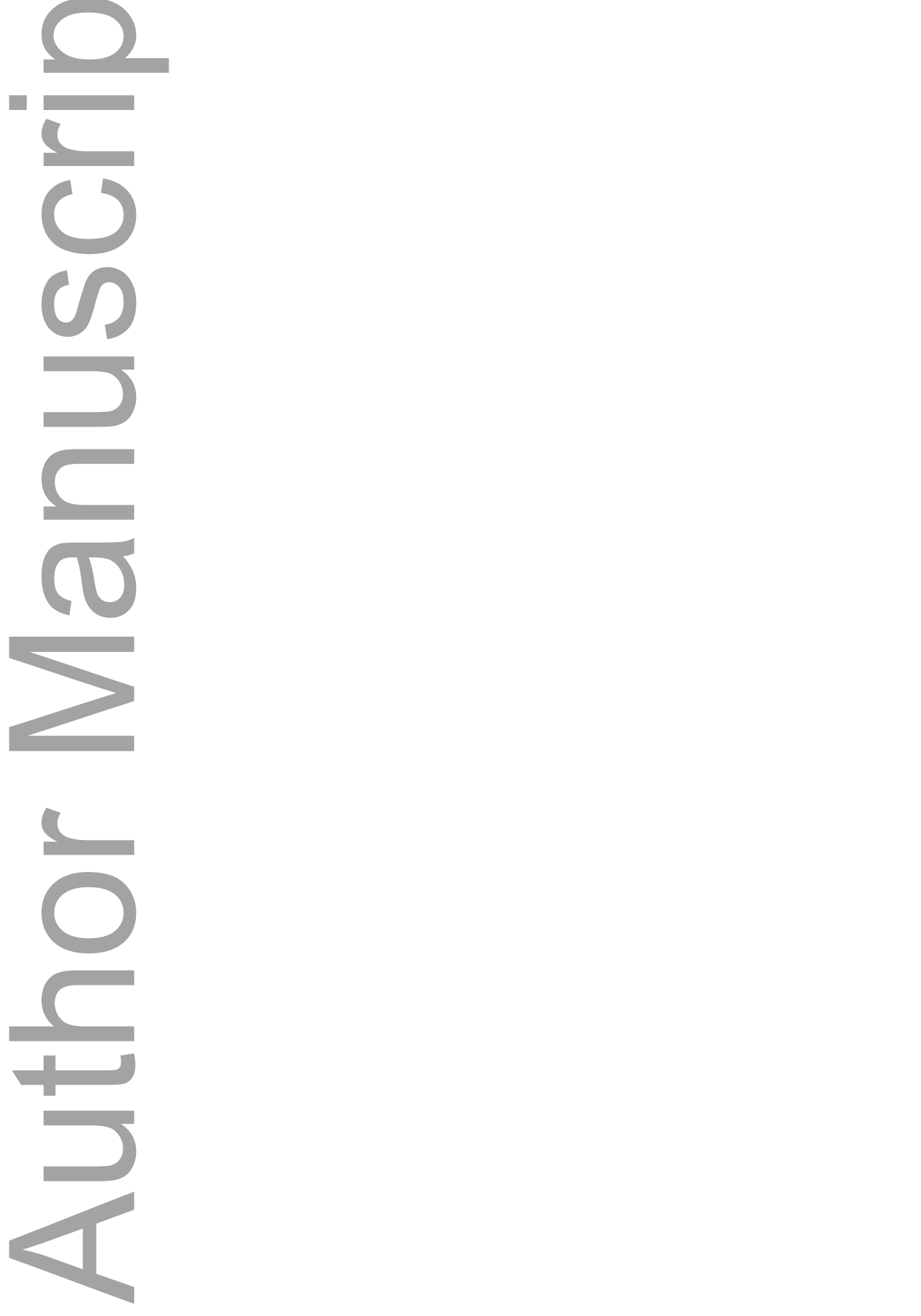

This article is protected by copyright. All rights reserved. 
Figure 1: Rank In the Wealth Distribution One Year before and One to Five Years after Asthma Diagnosis.
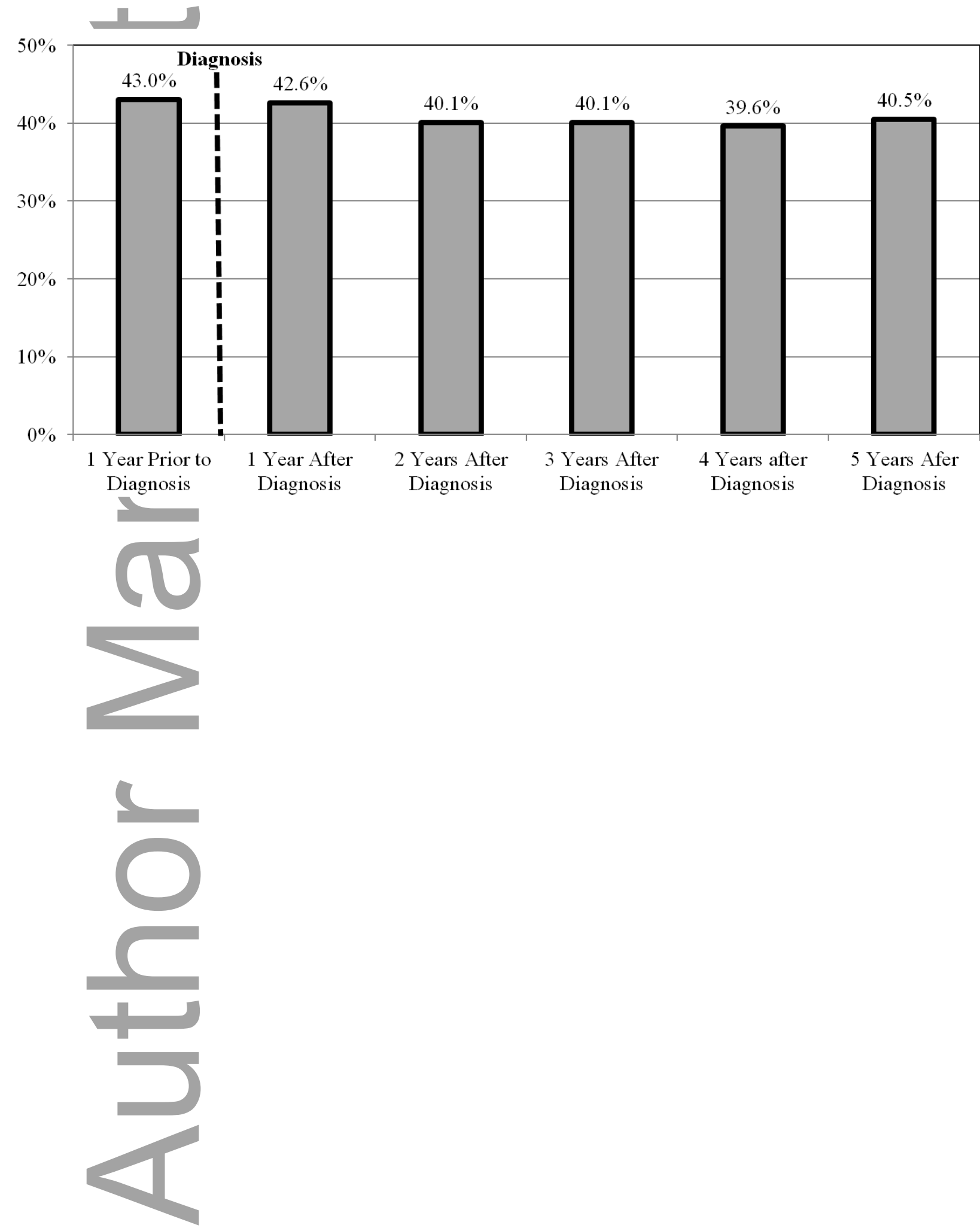

This article is protected by copyright. All rights reserved. 
Table 1: Adult Asthma Prevalence among NSLY79 Respondents

\begin{tabular}{|l|c|c|c|}
\hline & $\begin{array}{c}\text { Overall } \\
(\text { s.e. })\end{array}$ & $\begin{array}{c}\text { Men } \\
(\text { s.e. })\end{array}$ & $\begin{array}{c}\text { Women } \\
(\text { s.e. })\end{array}$ \\
\hline Ever Had Asthma & $\begin{array}{c}10.5 \% \\
(0.4 \%)\end{array}$ & $\begin{array}{c}8.0 \% \\
(0.5 \%)\end{array}$ & $\begin{array}{c}12.8 \% \\
(0.5 \%)\end{array}$ \\
\hline Current Asthma & $\begin{array}{c}7.6 \% \\
(0.3 \%)\end{array}$ & $\begin{array}{c}5.1 \% \\
(0.5 \%)\end{array}$ & $\begin{array}{c}9.9 \% \\
(0.5 \%)\end{array}$ \\
\hline Previous Asthma & $\begin{array}{c}2.9 \% \\
(0.2 \%)\end{array}$ & $\begin{array}{c}2.9 \% \\
(0.3 \%)\end{array}$ & $\begin{array}{c}2.9 \% \\
(0.3 \%)\end{array}$ \\
\hline Current Severe Asthma & $\begin{array}{c}3.6 \% \\
(0.2 \%)\end{array}$ & $\begin{array}{c}2.2 \% \\
(0.3 \%)\end{array}$ & $\begin{array}{c}5.0 \% \\
(0.4 \%)\end{array}$ \\
\hline Years of Asthma & $15.6 \mathrm{yrs}$ & $16.9 \mathrm{yrs}$ & $14.8 \mathrm{yrs}$ \\
& $(0.7)$ & $(1.2)$ & $(0.6)$ \\
\hline $\mathbf{N}$ & 7,644 & 3,667 & 3,977 \\
\hline
\end{tabular}

Notes: Years of Asthma applies only to those who ever reported having asthma. All values are weighted by the NLSY79 round 1 survey weight, which makes them nationally representative for this cohort. 
Table 2: Demographic Characteristics of Respondents by Asthma Status.

\begin{tabular}{|c|c|c|c|c|c|c|}
\hline 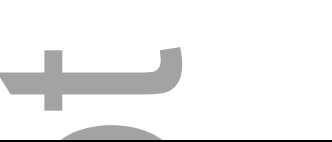 & Overall & $\begin{array}{c}\text { No } \\
\text { Asthma }\end{array}$ & $\begin{array}{c}\text { Ever Had } \\
\text { Asthma }\end{array}$ & $\begin{array}{c}\text { Currently } \\
\text { Have Asthma }\end{array}$ & $\begin{array}{l}\text { Previously } \\
\text { Had Asthma }\end{array}$ & $\begin{array}{l}\text { Current } \\
\text { Severe } \\
\text { Asthma }\end{array}$ \\
\hline White ${ }^{*}$ & $78.7 \%$ & $79.1 \%$ & $75.5 \%$ & $76.4 \%$ & $71.2 \%$ & $73.3 \%$ \\
\hline Black $^{* *}$ & $14.8 \%$ & $14.5 \%$ & $17.9 \%$ & $17.1 \%$ & $20.1 \%$ & $19.4 \%$ \\
\hline Hispanic & $6.5 \%$ & $6.4 \%$ & $7.1 \%$ & $6.5 \%$ & $8.7 \%$ & $7.3 \%$ \\
\hline Age & 42.7 & 42.7 & 42.6 & 42.6 & 42.7 & 42.8 \\
\hline Number Siblings & 3.3 & 3.3 & 3.2 & 3.2 & 2.9 & 3.3 \\
\hline$\%$ Female ${ }^{* * *}$ & $52.1 \%$ & $50.7 \%$ & $63.5 \%$ & $67.8 \%$ & $52.1 \%$ & $71.1 \%$ \\
\hline Income in $2004^{* * *}$ & $\$ 76,602$ & $\$ 77,937$ & $\$ 65,178$ & $\$ 61,806$ & $\$ 73,760$ & $\$ 52,371$ \\
\hline AFQT & 50.4 & 50.7 & 48.3 & 46.8 & 52.3 & 41.6 \\
\hline High School Degree & $90.9 \%$ & $90.9 \%$ & $88.4 \%$ & $87.8 \%$ & $94.7 \%$ & $83.6 \%$ \\
\hline Years of Schooling & 13.5 & 13.5 & 13.3 & 13.2 & 13.6 & 12.8 \\
\hline Married $^{* * *}$ & $64.8 \%$ & $65.9 \%$ & $55.8 \%$ & $54.5 \%$ & 59.1 & $49.7 \%$ \\
\hline Ever Divorced $^{* * *}$ & $33.7 \%$ & $33.1 \%$ & $38.9 \%$ & $43.1 \%$ & $41.7 \%$ & $51.7 \%$ \\
\hline Years Worked $^{* * *}$ & 19.7 & 19.9 & 18.0 & 17.5 & 19.2 & 16.7 \\
\hline Self Employed & $13.5 \%$ & $13.5 \%$ & $12.9 \%$ & $12.8 \%$ & $13.3 \%$ & $13.5 \%$ \\
\hline Live In Urban Area & $67.9 \%$ & $67.7 \%$ & $69.5 \%$ & $69.4 \%$ & $69.9 \%$ & $68.1 \%$ \\
\hline Live In South State & $36.5 \%$ & $36.8 \%$ & $34.3 \%$ & $34.5 \%$ & $33.7 \%$ & $34.5 \%$ \\
\hline Ever Smoke $e^{* *}$ & $58.3 \%$ & $57.8 \%$ & $62.2 \%$ & $62.4 \%$ & $61.7 \%$ & $68.0 \%$ \\
\hline Smoker In House & $3.1 \%$ & NA & $29.4 \%$ & $39.5 \%$ & $2.8 \%$ & $44.5 \%$ \\
\hline$N$ & 7,644 & 6,792 & 852 & 609 & 243 & 302 \\
\hline
\end{tabular}

Notes: All variables are weighted using the survey weights, except the number of respondents. ${ }^{* * *}$ indicates the values in the "no asthma" and "ever had asthma" columns are statistically distinct from each other at $p<0.01$ or higher level. ${ }^{* *}$ and ${ }^{*}$ are distinct at 0.05 and 0.10 levels respectively. 
Table 3: Respondent Wealth by Asthma Status in 2004.

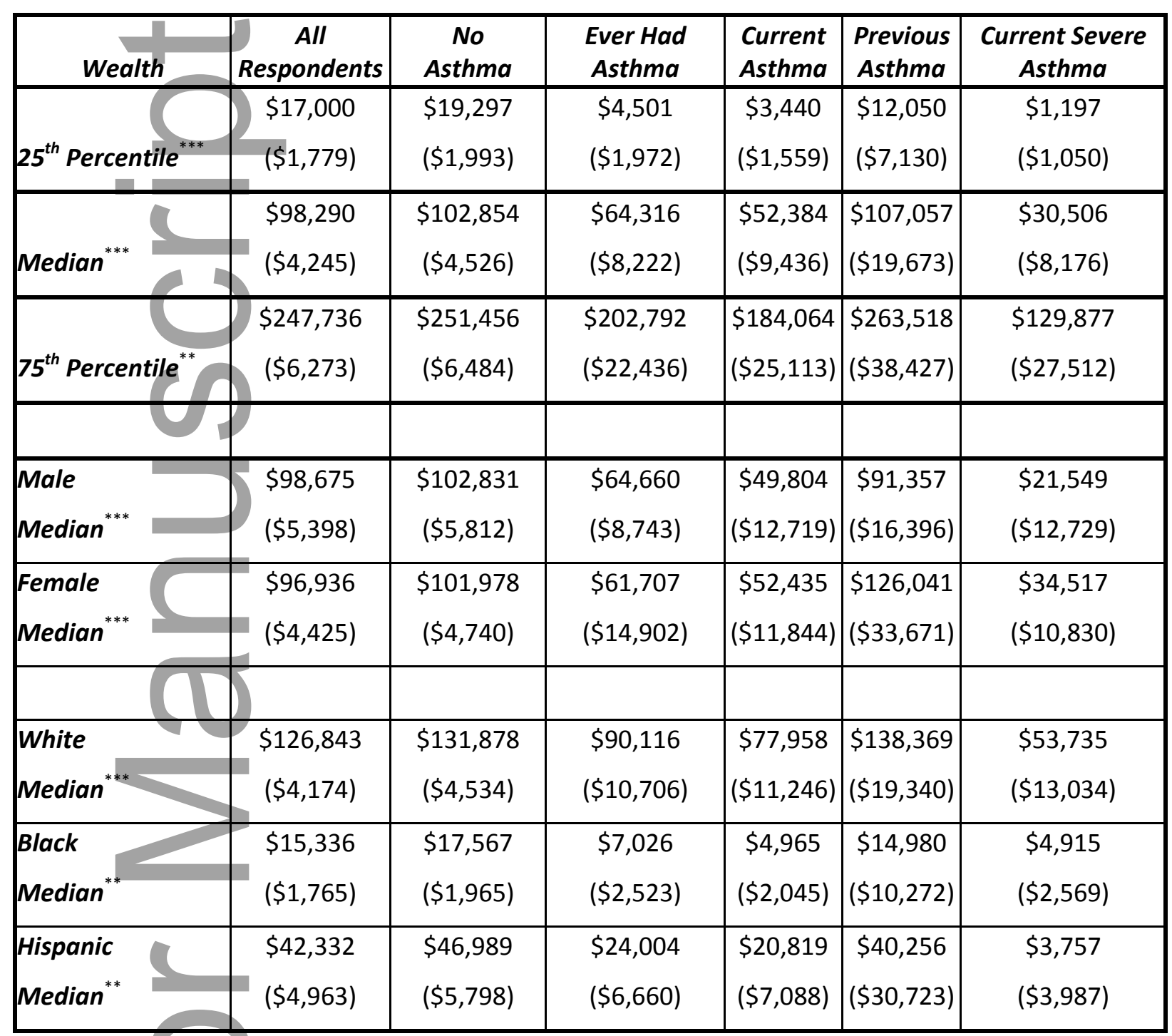

Notes: Standard errors are in ( ) and were calculated using Sudaan 9.0.

mean the values in the "no asthma" and "ever had asthma columns" are statistically distinct from each other at $p<0.01$ level, $* *$ means $p<0.05$.

This article is protected by copyright. All rights reserved. 
Table 4: Regressions Explaining Wealth in 2004.

\begin{tabular}{|c|c|c|c|c|c|}
\hline म & $\begin{array}{c}\text { (1) } \\
\text { Wealth }\end{array}$ & $\begin{array}{c}\text { (2) } \\
\text { Wealth }\end{array}$ & $\begin{array}{c}\text { (3) } \\
\text { Wealth }\end{array}$ & $\begin{array}{c}\text { (4) } \\
\text { Wealth }\end{array}$ & $\begin{array}{c}\text { (5) } \\
\text { Wealth }\end{array}$ \\
\hline Ever Have Asthma & $-\$ 12,834$ & & & & \\
\hline Current Asthma & & $-\$ 16,048$ & & & \\
\hline Previously Have Asthma & & & $-\$ 5,928$ & & \\
\hline Severe Asthma & & & & $-\$ 24,485^{* *}$ & $-\$ 20,348$ \\
\hline Years of Asthma & & & & & $-\$ 323$ \\
\hline Black & $-\$ 46,788^{* * *}$ & $-\$ 47,066^{* * *}$ & $-\$ 46,897^{* * *}$ & $-\$ 47,217^{* * *}$ & $-\$ 47,079^{* * *}$ \\
\hline Hispanic & $-\$ 11,645$ & $-\$ 11,804$ & $-\$ 11,936$ & $-\$ 11,806$ & $-\$ 11,199$ \\
\hline Age & $\$ 5,366^{* * *}$ & $\$ 5,359^{* * *}$ & $\$ 5,345^{* * *}$ & $\$ 5,404^{* * *}$ & $\$ 5,362^{* * *}$ \\
\hline Female & $\$ 2,527$ & $\$ 2,576$ & $\$ 2,029$ & $\$ 2,486$ & $\$ 2,946$ \\
\hline $\operatorname{Ln}\left(\operatorname{Income}{ }_{2003}\right)$ & $\$ 14,294^{* * *}$ & $\$ 14,277^{* * *}$ & $\$ 14,292^{* * *}$ & $\$ 14,290^{* * *}$ & $\$ 14,407^{* * *}$ \\
\hline AFQT & $\$ 689^{* * *}$ & $\$ 686^{* * *}$ & $\$ 687^{* * *}$ & $\$ 681^{* * *}$ & $\$ 674^{* * *}$ \\
\hline High School Graduate & $-\$ 17,729^{* * *}$ & $-\$ 17,707^{* * *}$ & $-\$ 17,797^{* * *}$ & $\$ 18,124^{* * *}$ & $-\$ 17,739^{* * *}$ \\
\hline Highest Grade Completed & $\$ 13,828^{* * *}$ & $\$ 13,835^{* * *}$ & $\$ 13,809^{* * *}$ & $\$ 13,849^{* * *}$ & $\$ 13,846^{* * *}$ \\
\hline Married & $\$ 69,832^{* * *}$ & $\$ 69,917^{* * *}$ & $\$ 69,959^{* * *}$ & $\$ 69,846^{* * *}$ & $\$ 69,847^{* * *}$ \\
\hline Ever Divorced & $-\$ 21,897^{* * *}$ & $-\$ 21,924^{* * *}$ & $-\$ 21,950^{* * *}$ & $-\$ 21,685^{* * *}$ & $-\$ 21,964^{* * *}$ \\
\hline Num. Siblings & $-\$ 2,228^{* * *}$ & $-\$ 2,220^{* * *}$ & $-\$ 2,164^{* * *}$ & $-\$ 2,218^{* * *}$ & $-\$ 2,356^{* * *}$ \\
\hline Years Worked & $\$ 1,772^{* * *}$ & $\$ 1,766^{* * *}$ & $\$ 1,795^{* * *}$ & $\$ 1,760^{* * *}$ & $\$ 1,773^{* * *}$ \\
\hline Self-Employed & $\$ 25,848^{* * *}$ & $\$ 25,843^{* * *}$ & $\$ 25,730^{* * *}$ & $\$ 25,690^{* * *}$ & $\$ 25,919^{* * *}$ \\
\hline Live In Urban Area & $-\$ 10,551^{*}$ & $-\$ 10,505^{*}$ & $-\$ 10,595^{*}$ & $-\$ 10,514^{*}$ & $-\$ 10,848^{*}$ \\
\hline Live In South & $-\$ 25,240^{* * *}$ & $-\$ 25,193^{* * *}$ & $-\$ 25,097^{* * *}$ & $-\$ 25,179^{* * *}$ & $-\$ 25,152^{* * *}$ \\
\hline Ever Smoke & $-\$ 16,999^{* * *}$ & $-\$ 17,098^{* * *}$ & $-\$ 16,802^{* * *}$ & $-\$ 16,954^{* * *}$ & $-\$ 17,176^{* * *}$ \\
\hline Smoker In Asthma Home & $\$ 3,582$ & $\$ 6,544$ & $\$ 8,158$ & $\$ 4,094$ & $\$ 7,944$ \\
\hline Intercept & $-\$ 429,815^{* * *}$ & $-\$ 426,267^{* * *}$ & $-\$ 436,306^{* * *}$ & $-\$ 419,542^{* *}$ & $-\$ 422,922^{* * *}$ \\
\hline & & & & & \\
\hline$R^{2}$ & 0.24 & 0.24 & 0.24 & 0.24 & 0.24 \\
\hline$N$ & 6,736 & 6,736 & 6,736 & 6,736 & 6,663 \\
\hline
\end{tabular}

Note: ${ }^{* * *}$ significant at the 0.01 or higher level, ${ }^{* *}$ significant at $0.05, *$ at 0.10 . 
Table 5: Relationship between Severe Asthma Prevalence and Receipt of Inheritance.

\begin{tabular}{|c|c|c|c|c|c|c|}
\hline $\begin{array}{c}\text { No } \\
\text { Substantial } \\
\text { Inheritance }\end{array}$ & $\begin{array}{c}\text { No } \\
\text { Severe } \\
\text { Asthma } \\
(1)\end{array}$ & $\begin{array}{c}\text { Have } \\
\text { Severe } \\
\text { Asthma } \\
\text { (2) }\end{array}$ & $\begin{array}{c}\text { Received } \\
\text { Substantial } \\
\text { Inheritance }\end{array}$ & $\begin{array}{c}\text { No } \\
\text { Severe } \\
\text { Asthma } \\
\text { (3) }\end{array}$ & $\begin{array}{c}\text { Have } \\
\text { Severe } \\
\text { Asthma } \\
\text { (4) }\end{array}$ & $\begin{array}{c}\text { Columns } \\
\text { (3) and (4) } \\
\text { Statistically } \\
\text { Distinct At }\end{array}$ \\
\hline $\begin{array}{c}\text { No } \\
\text { Inheritance } \\
\text { or }<\$ \mathbf{\$ 5 , 0 0 0}\end{array}$ & $\begin{array}{c}49.3 \% \\
(n=236)\end{array}$ & $\begin{array}{c}50.7 \% \\
(n=258)\end{array}$ & $\begin{array}{l}\text { Inherit } \\
\$ 5,000+\end{array}$ & $\begin{array}{l}62.0 \% \\
(n=71)\end{array}$ & $\begin{array}{l}38.0 \% \\
(n=44)\end{array}$ & $\mathrm{p}=5.6 \%$ \\
\hline $\begin{array}{c}\text { No } \\
\text { Inheritance } \\
\text { or }<\$ \mathbf{\$ 1 0 , 0 0 0}\end{array}$ & $\begin{array}{l}49.7 \% \\
(n=247)\end{array}$ & $\begin{array}{c}50.3 \% \\
(n=266)\end{array}$ & $\begin{array}{c}\text { Inherit } \\
\$ 10,000+\end{array}$ & $\begin{array}{l}62.9 \% \\
(\mathrm{n}=60)\end{array}$ & $\begin{array}{l}37.1 \% \\
(\mathrm{n}=36)\end{array}$ & $\mathrm{p}=6.3 \%$ \\
\hline $\begin{array}{c}\text { No } \\
\text { Inheritance } \\
\text { or }<\$ 25,000\end{array}$ & $\begin{array}{c}50.2 \% \\
(n=269)\end{array}$ & $\begin{array}{c}49.8 \% \\
(n=282)\end{array}$ & $\begin{array}{c}\text { Inherit } \\
\$ 25,000+\end{array}$ & $\begin{array}{l}66.2 \% \\
(n=38)\end{array}$ & $\begin{array}{l}33.8 \% \\
(\mathrm{n}=20)\end{array}$ & $\mathrm{p}=7.3 \%$ \\
\hline
\end{tabular}

